\title{
CORRELATION BETWEEN EBV CO-INFECTION AND HPV16 GENOME INTEGRITY IN TUNISIAN CERVICAL CANCER PATIENTS
}

\author{
Saloua Kahla ${ }^{1}$, Sarra Oueslati ${ }^{1}$, Mongia Achour ${ }^{1}$, Lotfi Kochbati ${ }^{2}$, Mohamed Badis Chanoufi ${ }^{3}$, Mongi Maalej $^{2}$, Ridha \\ Oueslati $^{1^{*}}$
}

${ }^{1}$ Unit of Immunology Microbiology Environmental and Carcinogenesis (IMEC), Science Faculty of Bizerte, University of Carthage, 7021 Jarzouna, Bizerte, Tunisia; ${ }^{2}$ Radio-oncology department, Salah Azaiz Institute, Tunis, Tunisia; ${ }^{3}$ Department of

Gynaecology Obstetrics A, Center of Maternity and Neonatology, Hospital La Rabta, Tunis, Tunisia.

Submitted: July 22, 2011; Returned to authors for corrections: September 22, 2011; Approved: June 07, 2012.

\begin{abstract}
Infection with high risk Human papillomavirus (HR-HPV) is necessary but not sufficient to cause cervical carcinoma. This study explored whether multiple HR-HPV or coinfection with Epstein-Barr virus (EBV) influence the integration status of HPV16 genome. The presence and typing of HPV in a series of 125 cervical specimens were assessed by polymerase chain reaction (PCR) using the specific primers for the HPV L1 region. As for EBV infection, the viral EBNA1 gene was used for its detection through PCR amplification. Disruption of the HPV E2 gene was assessed by amplification of the entire E2 gene with single set of primers, while E2 transcripts were evaluated by a reverse transcription PCR method (RT-PCR). The overall prevalence of HPVDNA was of $81.8 \%$ in cervical cancers versus $26.9 \%$ in benign lesions. In HPV positive cases, HPV16 and HPV18 were the most prevalent types, followed by HPV types 33, 31. EBV EBNA1 prevalence was statistically more frequent in cervical carcinomas than in benign lesions $(29.5 \%$, vs 9.6\%; $P=0.01$ ). No viral infection was detected in healthy control women. The uninterrupted E2 gene was correlated with the presence of E2 transcripts originating from the HPV episomal forms. It was observed that integration was more common in HPV18 and EBV coinfection. The presence of EBV caused a five-fold $[\mathrm{OR}=5 ; \mathrm{CI}=1.15-21.8 ; P=0.04]$ increase in the risk of HPV16 genome integration in the host genome. This study indicates that EBV infection is acting as a cofactor for induction of cervical cancer by favoring HPVDNA integration.
\end{abstract}

Key words: Cervical cancer, Epstein-Barr virus, E2 gene, E2 mRNA, High risk human papillomaviruses.

\section{INTRODUCTION}

Human papillomavirus (HPV) infection is a prerequisite for the development of cervical cancer (6). This association is strong, consistent, and specific to a limited number of viral types $(9,26)$, in which HPV16 and HPV18 are the most prevalent $(23,14,48)$. Geographic differences in the frequencies of other high-risk HPV types, including HPV 31,

*Corresponding Author. Mailing address: Unit of Immunology and Microbiology Environmental and Carcinogenesis (IMEC), Science Faculty of Bizerte, University of Carthage, 7021 Jarzouna, Bizerte, Tunisia.; E-mail: oridha2003@yahoo.fr 
33 , and 45 , have been reported to exist $(10,26)$. Nearly all women will become infected with HPV during their lifetime but only a minority of these infections will progress to invasive cancers. Therefore, there is a continuing need for the identification of viral and host factors that modulate the risk of disease progression (11). Possible agents included Herpes viruses among which more recently Epstein-Barr Virus (EBV), have been suspected to participate in cervical carcinogenesis $(15,33,31,13)$. For example, latent infection with EBV has been shown to act as a carcinogenic cofactor in several epithelial cell malignancies (38). The viral EBNA1 regulator of EBV transcription and replication is typically expressed in most forms of EBV-positive malignancies (24). On the other hand, integration of HPV DNA into the human genome is considered an essential step in the progression of HPVassociated cervical infection to invasive cervical carcinoma (18, 41). Upon integration the viral E2 gene, encoding a transcriptional repressor, is often disrupted with loss of its repressor function thus leading to up regulation of the transcription of the E6 and E7 oncogenes (30, 12). High expression of the viral oncogenes leads to disturbance of cell cycle controls and genomic instability that increase the risk of malignant transformation $(25,29)$. The main goal of our study was to explore frequency distribution of HR HPV genotypes and EBV infection in cervical cancer and premalignant lesions in order to correlate them with HPV 16 physical state.

\section{MATERIALS AND METHODS}

\section{Sample Collection and Study Population}

This study enrolled 44 patients with cervical carcinoma recruited from the Radio-oncology department of Salah Azaiez Institute (Tunis, Tunisia). The mean patient age was 57.2 years (range: 38-76 years). Tumor specimens have been collected by punch biopsy, which consisted of 39 squamous cell carcinomas and 5 adenocarcinomas. Stages of the disease were coded according to International Federation of Gynecology and
Obstetrics (FIGO). None malignant cervical biopsies were obtained from 52 women attending the Obstetrics and Gynecology Department of La Rabta Hospital (Tunis, Tunisia) for reasons other than cervical cancer. Also twenty nine Healthy controls women, counseling for routine reproductive healthcare, were used as reference. The range of ages varied from 27 to 56 years old, with an average of 41 years. Controls had no past or current history of cervical abnormalities. Biopsy specimens were transferred into cryotubes, suspended in $1 \mathrm{ml}$ PBS (phosphate-buffered saline, $\mathrm{pH}$ 7.4) and stored frozen at $20^{\circ} \mathrm{C}$ until analysis.

\section{DNA and RNA isolation}

DNA extraction was performed using the QIAamp system, QIAamp DNA Mini Kit (Qiagen, Hilden, Germany), according to standard procedures as described in the kit, with detergent lysis buffer and proteinase $\mathrm{K}$ digestion. Total DNA was eluted in $100 \mu \mathrm{l}$ of elution buffer and stored frozen at $-20^{\circ} \mathrm{C}$. RNA from frozen tissues was isolated using RNeasy Mini Kit (Qiagen, Hilden, Germany) as recommended by the supplier and dissolved in $30 \mu \mathrm{l}$ RNase free water.

The quality and quantity of the target nucleic acids were assessed by agarose gel electrophoresis and optical density measurement (absorbance at $260 \mathrm{~nm}$ ).

\section{HR-HPV typing and EBV detection}

Purified genomic DNA was amplified using PCR technique for the HR HPVL1 and EBV EBNA1 genes (synthesized by GeneCust Europe, Dudelange, Luxembourg) using specific primers, as well as for the internal reference $\beta$ globin gene, to determine whether the isolated DNA was suitable for amplification. Thermal cycles were performed in a programmable PCR thermal cycler (Applied Biosystem, Foster City, USA), as previously described (46, 21). Each PCR experiment was performed with positive (HPV plasmids, cervical carcinoma previously proved to contain EBV) and negative (Blank water) controls. Samples tested positive for the 
$\beta$-globin DNA control, confirming that none of the samples amplicon sizes and cycling programs are illustrated in Table 1. was inhibitory for PCR or lacked DNA. The Primer sequences,

Table 1. Polymerase Chain Reaction and Reverse Transcription primers, product length and programs.

\begin{tabular}{|c|c|c|c|}
\hline Primers for PCR assay & Designation & Product length (bp) & PCR program \\
\hline HPV 16 L1 sense & 5'-GCAAGCAACAGTTACTGCGACGT-3' & \multirow{2}{*}{301} & \multirow{2}{*}{$94^{\circ} \mathrm{C} 1^{\prime}, 58^{\circ} \mathrm{C} 1^{\prime}, 72^{\circ} \mathrm{C} 1^{\prime} ; \mathrm{X} 40$} \\
\hline HPV16 L1 anti-sense & 5'-GCAACAAGACATACATCGACCGG-3' & & \\
\hline HPV18 L1 sense & 5'-AAGGATGCTGCACCGGCTGA-3' & \multirow{2}{*}{217} & \multirow{2}{*}{$94^{\circ} \mathrm{C} 1^{\prime}, 66^{\circ} \mathrm{C} 1^{\prime}, 72^{\circ} \mathrm{C} 1^{\prime} ; \mathrm{X} 40$} \\
\hline HPV18 L1 anti-sense & 5'-CACGCACACGCTTGGCAGGT-3' & & \\
\hline HPV31 L1 sense & 5'-CGTCCMARRGGAWACTGATC-3' & \multirow{2}{*}{254} & \multirow{2}{*}{$95^{\circ} \mathrm{C} 1^{\prime}, 55^{\circ} \mathrm{C} 1^{\prime}, 72^{\circ} \mathrm{C} 1^{\prime} ;$; 35} \\
\hline HPV31 L1 anti-sense & 5'-TGTTTGTGCTGCAATTGCAAACAGTGATAC-3' & & \\
\hline HPV33 L1 sense & 5'-CGTCCMARRGGAWACTGATC-3' & \multirow{2}{*}{111} & \multirow{2}{*}{$95^{\circ} \mathrm{C} 1^{\prime}, 55^{\circ} \mathrm{C} 1^{\prime}, 72^{\circ} \mathrm{C} 1^{\prime} ; \mathrm{X} 35$} \\
\hline HPV33 L1 anti-sense & 5'-TTTATGCACACAAGTAACTAGTGACAGTAC-3' & & \\
\hline HPV45 L1 sense & 5'-CGTCCMARRGGAWACTGATC-3' & \multirow{2}{*}{402} & \multirow{2}{*}{$95^{\circ} \mathrm{C} 1^{\prime}, 55^{\circ} \mathrm{C} 1^{\prime}, 72^{\circ} \mathrm{C} 1^{\prime} ; \mathrm{X} 35$} \\
\hline HPV45 L1 anti-sense & 5'-ACACAAAATCCTGTGCCAAGTACATATGAC-3' & & \\
\hline$\beta$ Globin sense & 5'-CAACTTCATCCACGTTCACC-3' & \multirow{2}{*}{268} & \multirow{2}{*}{$95^{\circ} \mathrm{C} 1^{\prime}, 55^{\circ} \mathrm{C} 1^{\prime}, 72^{\circ} \mathrm{C} 1^{\prime} ; \mathrm{X} 40$} \\
\hline$\beta$ Globin anti-sense & 5'-GAAGAGCCAAGGACAGGTAC-3' & & \\
\hline EBV EBNA1 sense & 5'-TGATAACCATGGACGAGGAC-3' & \multirow{2}{*}{138} & \multirow{2}{*}{$94^{\circ} \mathrm{C} 1,, 58^{\circ} \mathrm{C} 40 \mathrm{~s}, 72^{\circ} \mathrm{C} 40 \mathrm{~s} ; \mathrm{X} 35$} \\
\hline EBV EBNA1 anti-sense & 5'-CTTCAAGTTGCATTGGCTGC-3' & & \\
\hline HPV16 E2 sense & 5'-ATGAAAATGATAGTACAGAC-3' & \multirow{2}{*}{1026} & \multirow{2}{*}{$95^{\circ} \mathrm{C} 1^{\prime}, 50^{\circ} \mathrm{C} 2^{\prime}, 72^{\circ} \mathrm{C} 1^{\prime} 30 ;$ X 35} \\
\hline HPV16 E2 anti-sense & 5'-CCAGTAGACACTGTAATAG-3' & & \\
\hline \multicolumn{4}{|c|}{ Primers for RT PCR assay } \\
\hline HPV 16 E2 sense & 5'-GAACTGCAACTAACGTTAGA-3' & \multirow{2}{*}{149} & \multirow{2}{*}{$94^{\circ} \mathrm{C} 40 \mathrm{~s}, 60^{\circ} \mathrm{C} 1^{\prime}, 72^{\circ} \mathrm{C} 1^{\prime} ; \mathrm{X} 40$} \\
\hline HPV16 E2 anti- sense & 5'-TCCATCAAACTGCACTTCCA-3' & & \\
\hline$\beta$ Actin sense & 5'-AGCCATGTACGTTGCTATCC-3' & \multirow{2}{*}{500} & \multirow{2}{*}{$94^{\circ} \mathrm{C} 30 \mathrm{~s}, 50^{\circ} \mathrm{C} 30 \mathrm{~s}, 72^{\circ} \mathrm{C} 1^{\prime} ; \mathrm{X} 30$} \\
\hline$\beta$ Actin anti-sense & 5'-TTGGCGTACAGGTCTTTGC-3' & & \\
\hline
\end{tabular}

\section{Assessment of HPV16 E2 DNA and RNA integrity}

Adapting an approach previously described (4), the integrity of E2 gene was assessed using a single set of sequence-specific primers that were designed to amplify Open Reading Frame (ORF) fragments spanning the full length of HPV16 E2 gene (Table 1).

All positive samples for HPV $16 \mathrm{~L} 1$ expression were subjected to PCR amplification of the E2 ORF region. The presence of E2 amplicon in agarose gel confirmed an intact E2 gene, while lack of specific band indicated disruption. HPV16 positive samples were further subjected to amplification of E2 transcripts (28). To control RNA integrity, RT-PCR reactions using $\beta$-actin specific primers were performed (34). One microgram total RNA was reverse-transcribed using the one step RT PCR Kit (Qiagen, Hilden, Germany). The amplified products were electrophoresed on a $1.5 \%$ agarose gel, marked by a 100-pb DNA ladder (Gene Ruler ${ }^{\mathrm{TM}}$, Fermentas, Foster City, USA), stained with ethiduim bromide, and visualized under UV light. Images were recorded by using the Photo documentation system (Doc-Print II, VILBER LOURMAT, Marne-la-Vallée, France).

Several precautions were taken to prevent false positive results. Different steps, such as sample preparation, nucleic acid extraction, amplification and post PCR, were performed in strictly separated rooms.

\section{Statistics}

Data were analyzed using SPSS, version 18.0 for windows 
Vista. The associations between the variables were assessed using Fisher's exact test. Odds Ratios (OR) and corresponding 95\% Confidence Intervals (CI) were estimated by logistic regression models. A stepwise logistic regression analysis was used to assess the simultaneous effect of more than one variable and to identify for possible confounding factors. In all analyses, probability values less than 0.05 were regarded as significant.

\section{RESULTS}

\section{Frequencies of HR-HPV DNA and EBV in cervical samples}

By using the primers directed against the highly conserved L1 gene, we detected 4 different HPV types in our collection of samples. Overall 36 out of 44 cervical cancer samples $(81.8 \%)$ were HPV positive. HPV type 16, the most frequent type of oncogenic HPV, was found in 24 cases (54.5\%) while HPV18 ranked second with a rate of $15.9 \%$ (7/44). Less frequent types including HPV 33, and HPV31 were also found in $6.8 \%, 4.5 \%$ of the samples respectively while HPV45 was not detected.
Double infection was found in 5 cases of HPV16 and 18 in 3 cases and HPV 16 and 33 in 2 cases.

From the benign cervical lesions, $21.1 \%$ were positive for HPV16 (11/52), while 5.7\% were positive for HPV18 (3/52). One sample containing both HPV type 16 and 18 was found. Among the control group, no viral infection was detected. The results of HPV typing are summarized in Table 2.

Our results indicate a significant increase in detection of HR-HPV in cancers compared to non malignant samples $(P<$ $0.01)$.

The detection rate of EBV EBNA1 in tissue samples from cervical cancer patients was more frequent than that in non malignant samples $(29.5 \%$ vs, $9.6 \%, P=0.01)$. In addition, EBV EBNA1 was not found in any of the control samples. According to the Odd Ratio (OR) [3.9 (1.28-12.16)], women infected with EBV have a three-fold likelihood to develop cervical carcinoma.

A synergistic action of HPV16 and EBV may also occur in some cervical carcinomas $(22.7 \%)$, containing both EBV and HPV16 DNA versus only $7.6 \%$ in the benign samples.

Table 2. Prevalence of HR-HPV types and EBV in cervical carcinomas and controls

\begin{tabular}{|c|c|c|c|c|}
\hline & $\begin{array}{c}\text { Controls } \\
(\mathrm{N}=29) \\
\end{array}$ & $\begin{array}{c}\text { Non malignant } \\
(\mathrm{N}=52)\end{array}$ & $\begin{array}{c}\text { Cervical Cancer } \\
(\mathrm{N}=44)\end{array}$ & $P$ values \\
\hline HPV types & 0 & $14(26.9)$ & $36(81.8)$ & \\
\hline 16 & 0 & $11(21.1)$ & $24(54.5)$ & \\
\hline 18 & 0 & $3(5.7)$ & 7 (15.9) & \\
\hline 31 & 0 & 0 & $2(4.5)$ & $P<0.01 *$ \\
\hline 33 & 0 & 0 & $3(6.8)$ & \\
\hline 45 & 0 & 0 & 0 & \\
\hline EBV & 0 & $5(9.6)$ & $13(29.5)$ & $0.01 *$ \\
\hline Multiple infections & 0 & $5(9.6)$ & $15(34)$ & \\
\hline HPV16 \& HPV18 & 0 & $1(1.9)$ & $3(6.8)$ & \\
\hline HPV16 \& HPV33 & 0 & 0 & $2(4.5)$ & $0.004 *$ \\
\hline EBV \& HPV16 & 0 & $4(7.6)$ & $10(22.7)$ & \\
\hline
\end{tabular}

Correlation between HPV16 E2 physical state and episomal derived transcripts

Integrated forms of HPV16 DNA were predominant in cervical cancers, constituting $62.5 \%(15 / 24)$, whereas episomal forms were detected in 9 cases $(37.5 \%)$. Among benign lesions, 2 of the 11 HPV16 positive cases (18.1\%) showed E2 disruption, while episomal forms were noted in 9 cases $(81.8 \%)$. Thus, E2 disruption was significantly higher among cancers as expected $[P=0.02, \mathrm{OR}(95 \% \mathrm{CI})=7.5(1.32-42.77)]$ Table 3. We then decided to verify transcriptional expression of E2 in HPV16- associated lesions using RT-PCR.

All samples were found positive for the $\beta$-actin RNA 
control, which was included to avoid false-negative results due to degradation of RNA (not shown). HPV16 E2 mRNAs were expressed in the presence of the intact virus with episomal forms and E2 transcripts originate only from the episomal HPV16 DNA. In Figure 1A and Figure 1B, 6 of the 18 HPV16E2 positive cervical cases (lanes 1-6) are shown as examples.

Presence of the intact HPV16 E2 DNA, flanking the 1026- bp segments of the ORF fragment, was finally confirmed by HPV16 E2 RNA using primers giving an amplified product of $149 \mathrm{bp}$. In general amplification of E2 with RT-PCR appeared more sensitive than amplification of the DNA-PCR method for detection of intact HPV E2 gene, because E2 DNA signals from RT-PCR are usually stronger than those from DNA-PCR (Figure 1 A, Figure 1B).

Table 3. E2-gene status in human papillomavirus type-16 positive benign lesions and cancers

\begin{tabular}{|c|c|c|c|c|c|}
\hline \multirow[t]{2}{*}{ Parameters } & \multirow{2}{*}{$\begin{array}{c}\text { Total } \\
\mathbf{N}\end{array}$} & \multicolumn{2}{|c|}{$\begin{array}{c}\text { Physical status of HPV16 DNA } \\
(\%)\end{array}$} & \multirow[t]{2}{*}{ OR $(95 \% \mathrm{CI})$} & \multirow[t]{2}{*}{$P$ Value } \\
\hline & & Episomal & Integrated & & \\
\hline $\begin{array}{c}\text { Benign cervical lesions } \\
\text { Cervical cancers }\end{array}$ & $\begin{array}{l}11 \\
24\end{array}$ & $\begin{array}{l}9(81.8) \\
9(37.5)\end{array}$ & $\begin{array}{c}2(18.1) \\
15(62.5)\end{array}$ & $7.5(1.32-42.77)$ & $0.02 *$ \\
\hline
\end{tabular}
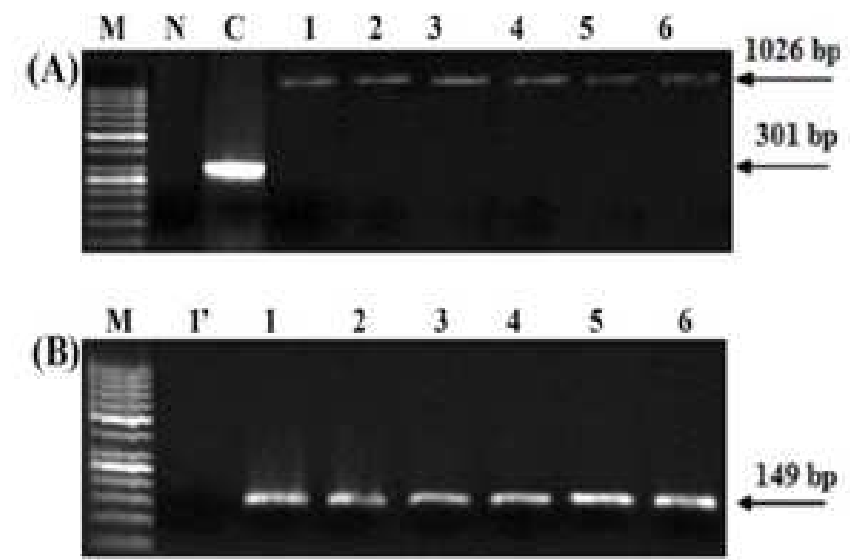

Disruption of the E2 gene together with multiple HR HPV or EBV coinfections predict carcinogenic progression

To analyze whether viral factors might have an influence on the integration status, we correlated disruption of the HPV16 genome with multiple HR HPV and EBV coinfections.

Such analysis revealed that HPV18 coinfection was found more often associated with HPV16 integration, while in contrast, HPV33 coinfection was only associated with HPV16
Figure 1. Detection of HPV 16 physical status. (A) PCR products of HPV16 episomal forms from cervical cancer positive samples: lanes 1-6 (amplicon length 1026 bp); M, Size markers of 100 bp ladder; N, Negative control (no template); C, positive control (HPV16 plasmid).

(B) Transcripts product for positive HPV16 E2 confirming PCR results: lanes 1-6 (amplicon length 149 bp); lane 1', indicative of integrated form witch was used as control.

episomal forms (Figure 2). We also correlated the presence of EBV to the status of the HPV16 genome in coinfected lesions. Interestingly, EBV was more frequently present in samples with integrated forms of HPV16 than in the episomal forms. Based on these data, EBV infection was significantly associated with disruption of the HPV16 genome as revealed by $\mathrm{OR}(95 \% \mathrm{CI})$ and $P$ values $[\mathrm{OR}=5 ; \mathrm{CI}=1.15-21.8 ; P=$ 0.04] Table 4. EBV could therefore be considered as a cofactor 
of disease risk as determined by the OR based on logistic regression models. The presence of EBV also may increases the probability of integrated HPV16 genome.
In conclusion of our analysis, EBV may play a cooperative role in HPV16 carcinogenic progression by favoring HPV16 DNA integration in the cellular genome.

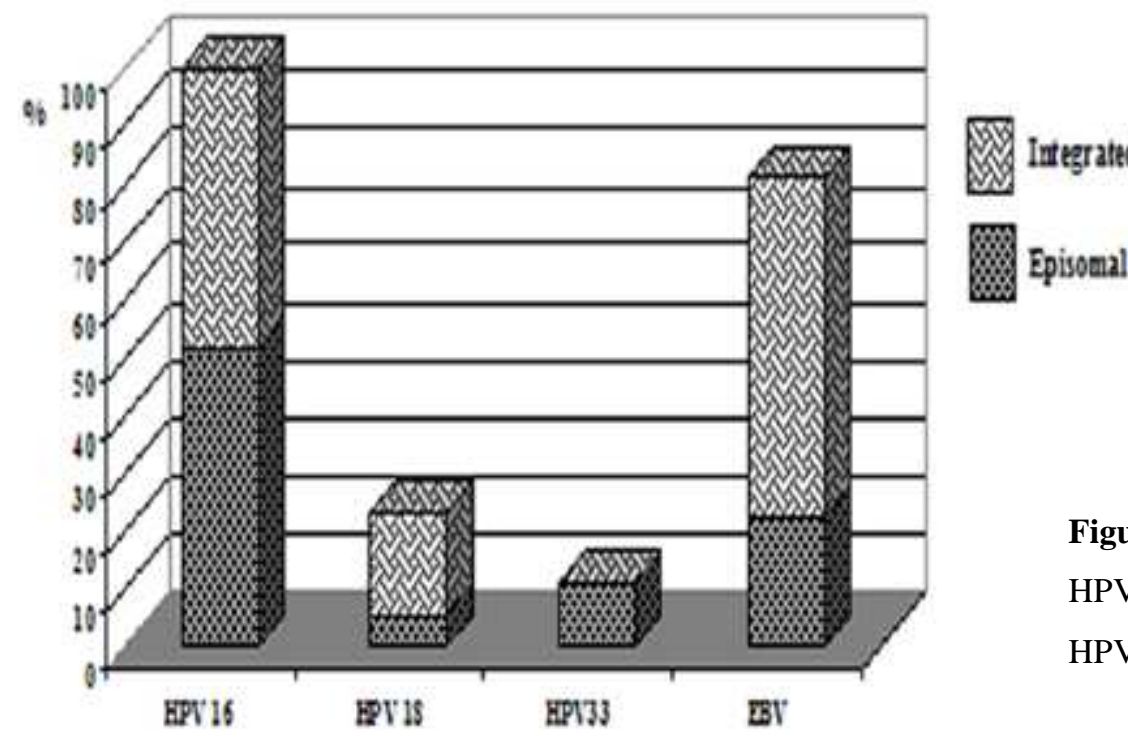

Figure 2. Frequency distribution of HR HPV types and EBV correlated with HPV16 DNA physical status.

Table 4. Distribution of EBV positive and negative cervical specimens correlated with HPV 16 DNA physical status

\begin{tabular}{|c|c|c|c|c|c|}
\hline \multirow{2}{*}{$\begin{array}{c}\text { HPV16 Physical } \\
\text { status }\end{array}$} & \multirow{2}{*}{$\begin{array}{c}\text { Total } \\
\mathbf{N}\end{array}$} & \multicolumn{2}{|c|}{ EBV } & \multirow{2}{*}{ OR $(95 \% \mathrm{CI})$} & \multirow{2}{*}{$P$ Value } \\
\hline & & Positive & Negative & & \\
\hline $\begin{array}{c}\text { Episomal } \\
\text { Integrated }\end{array}$ & $\begin{array}{l}18 \\
17\end{array}$ & $\begin{array}{c}4(22.2) \\
10(58.8)\end{array}$ & $\begin{array}{c}14(77.7) \\
7(41.1)\end{array}$ & $5(1.15-21.8)$ & 0.04 \\
\hline
\end{tabular}

$\boldsymbol{P}$ : two-sided Fisher's exact test

\section{DISCUSSION}

Infection with HR HPV is a necessary but not sufficient cause of cervical carcinoma, with additional viral and host genetic events required to drive cells to the malignant phenotype (47). In this report, we confirmed that HPV16 and 18 are the two most frequently detected types among cervical carcinoma in Tunisia, and that they account for $70.4 \%$, which is very similar to the proportion estimated in other world regions by recently published large Meta analyses $(23,14)$. To a lesser extent, HPV31 and HPV33 were detected in $11.3 \%$ of all cases, whereas HPV45 was not found. Similar data have been described for HPV31, 33, 35, 45, 52 and 58, which can be grouped in several branches differing in geographic distribution, and in relative prevalence within different ethnical groups $(7,8)$. HPV18 is the primary HPV type associated with cervical adenocarcinomas and its related type HPV45 (alpha 7 species) shows a similar rate of association (42). Interestingly, our pathological data demonstrate larger predominance of squamous cell carcinoma over adenocarcinomas in our samples, Furthermore the presence of HPV in benign cervical lesions has been widely documented. In our study, type 
specific HPV prevalence was similar to that found in aggregative analysis, where HPV 16/18 are the most frequent types observed $(39,40)$.

Although the role of high risk HPV infection in cervical cancer is well documented, the role of multiple infection has been less studied. Multiple HPV infection has been found to be associated with persistence of HPV infection that is a prerequisite for neoplastic transformation $(2,17)$. That report detected multiple HPV infection in $11.3 \%$ of cervical cancer patients. In other reports, the rate of multiple HPV infection in invasive cervical cancers ranged between $0 \%$ and $36 \%$ (32). Thus, multiple HR HPV infections ought to be more relevant for HPV18. Women coinfected with HPV16 and HPV18 are at significantly higher risk of developing CIN3 and cancer when compared to women infected with other high-risk types (22).

Interestingly, infection with HPV 33 was almost exclusively detected as part of multiple HPV infection. Only one patient had HPV type 33 as a single infection among the three cases detected. One explanation as to why HPV type 33 was a common element of multiple infections may be that HPV 33 usually occurs in combination with phylogenetically closely related types (HPV16, 31, 35 and 58). On the other hand, HPV31 was considerably less common in cervical carcinoma, as seen in previous studies (20), suggesting that in Tunisian populations, it has only a relatively weak carcinogenic potential in comparison to other types. Only one non malignant lesion was shown to harbor HPV16/18 coinfection. It is likely that this specific benign lesion is at risk of carcinogenic progression.

Otherwise, prevalence of HR HPV types alone does not give an accurate picture of the carcinogenic state of the lesion. In this regard, studies of the physical status of the HPV genome could help evaluating the risk of cervical carcinogenesis. Our findings confirmed earlier reports on association of disruption of the E2 gene with cervical cancer, wherein squamous cell carcinomas harbored $62.5 \%$ disruption in contrast to $18.1 \%$ in benign lesions. These data are in agreement with the report by
Nagao et al., (27), who showed an increase of integrated forms of HPV16 in parallel with the disease progression. The HPV E2 protein plays a crucial role in the viral life cycle as a transcription and a replication factor. E2 was also shown to be able to shuttle from the nucleus, to the cytoplasm where it activates caspase 8 , thus inducing apoptosis $(5,36,37)$. The HPV16 E2 protein has also been shown to be expressed at relatively high levels in benign lesions compared to cancers (45). Consequently, the detection of HR-HPV E2 transcripts might serve as an additional biomarker of cervical diseases. Results from the current study also indicate that the transcriptional activity of HPV16 E2 is a more sensitive indicator of the genomic disruption than analyses of the genomic DNA. When cervical carcinomas coinfected by HPV16 and HPV18 were investigated we could show that HPV18 coinfection was more likely linked to HPV16 integrated forms. It was previously established that HPV16 is present exclusively in episomal forms in $30-70 \%$ of cervical cancer $(3,43)$, whereas HPV18 has been reported to be mainly integrated (3), which indicates that these HPV types might have different biological characteristics. Meanwhile, some data have indicated that patients infected with HPV18 showed a rapid progression through precancerous stages (44). In contrast, HPV33 was found substantially more frequently associated with HPV16 episomal forms, in comparison with HPV18. It is in good agreement with the observation that cancers associated with HPV16 and HPV18 tend to be more aggressive, and that the detection of HPV types other than 16 and 18 is an independent predictor of better survival in patients with cervical carcinoma (19). Portraying the presence of intact E2 genes in almost $37.5 \%$ of HPV16 positive cervical cancer cases, have subsequently paved the way for new paradigms of cervical carcinogenesis.

A putative role of cooperative factors such as interaction with co infecting viruses, possibly at different stages of cervical carcinogenesis is demonstrated here. Previously, EBV, an oncogenic herpes virus, has been suggested as a possible 
viral cofactor (35). The fact that the EBV/C3d receptor was shown to be expressed in cervical epithelial samples, as well as the clear EBV linkage with epithelium originated tumors, made this hypothesis plausible (15). However, other authors did not reach to the same conclusion, confirming that EBV was acting in cervical tumor pathogenesis (33). The absence of EBV infection in controls and the decline of EBV peak in benign cervical lesions suggest that EBV infection occurs late in cervical oncogenesis. It may be that the EBV virus is acting as a cofactor of HPV, in induction of uterine cervix pathology; the suggestion was confirmed by studies of Szkaradkiewicz et al., (35), which report a possible sexual route for transmission of EBV. However, there is no convincing evidence to support the hypothesis that EBV infection plays a direct role in the pathogenesis of cervical neoplasia. Though, EBV-infected tumour infiltrating lymphocytes might contribute indirectly to cervical carcinogenesis via producing viral IL-10 expressed from the BamHI-C fragment rightward reading frame 1 gene (BCRF-1), which causes a reduction in local immunity leading to suppression of the response to HPV-transformed cells (1). This, together with the fact that EBV infection may contribute in the integration of HPV16 genome occurrence, suggests that, although they might not be involved in the oncogenic processes directly, they might play a role as cofactor. Accordingly, the viral EBV EBNA1 protein has been shown to be able to decrease apoptosis and DNA repair in EBV-associated lesions thus potentially contributing to malignant transformation of cotransfected EBV/HPV lesions (16).

In summary, further knowledge of markers of HPV genomic integration has the potential to improve objective management of cervical neoplasia. The data presented here might also be beneficial to our understanding of the biology of human neoplasms associated with integration of other DNA tumor viruses.

List of abbreviations: EBV: Epstein-Barr virus; RT-PCR: reverse transcription polymerase chain reaction; PBS: phosphate-buffered saline; HPV: human papillomavirus.

\section{ACKNOWLEDGEMENTS}

Special thanks to Pr Françoise THIERRY, Principal Investigator, Institute of Medical Biology, Biomedical Grove, Singapore, for constructive discussions and comments on the manuscript. The authors thank the medical personnel who have contributed to the collecting and assessment of the specimens. Financial support for this work was provided by grant from Ministry of Higher Education and Scientific Research in Tunisia.

\section{REFERENCES}

1. Al-Daraji, W.I.; Smith, J.H. (2009). Infection and cervical neoplasia: facts and fiction. Int. J. Clin. Exp. Pathol. 2 (1), 48-64.

2. Bachtiary, B.; Obermair, A.; Dreier, B.; Birner, P.; Breitenecker, G.; Knocke, T.H.; Selzer, E.; Pötter, R. (2002). Impact of multiple HPV infection on response to treatment and survival in patients receiving radical radiotherapy for cervical cancer. Int. J. Cancer. 102 (3), 237-243.

3. Badaracco, G.; Venuti, A.; Sedati, A.; Marcante, M.L. (2002). HPV16 and HPV18 in genital tumors: Significantly different levels of viral integration and correlation to tumor invasiveness. J. Med. Virol. 67 (4), 574-582.

4. Bhattacharjee, B.; Sengupta, S. (2006). HPV16 E2 gene disruption and polymorphisms of E2 and LCR: some significant associations with cervical cancer in Indian women. Gynecol. Oncol. 100 (2), 372-378.

5. Blachon, S.; Bellanger, S.; Demeret, C.; Thierry, F. (2005). Nucleocytoplasmic shuttling of high risk human Papillomavirus E2 proteins induces apoptosis. J. Biol. Chem. 280 (43), 36088-36098.

6. Bosch, F.X.; de Sanjosé, S. (2003). Chapter 1: Human papillomavirus and cervical cancer burden and assessment of causality. J. Natl. Cancer. Inst. Monogr. 31, 3-13.

7. Calleja-Macias, I.E.; Kalantari, M.; Huh, J.; Ortiz-Lopez, R.; RojasMartinez, A.; Gonzalez-Guerrero, J.F.; Williamson, A.L.; Hagmar, B.; Wiley, D.J.; Villarreal, L.; Bernard, H.U.; Barrera-Saldaña, H.A. (2004). Genomic diversity of human papillomavirus-16, 18, 31, and 35 isolates in a Mexican population and relationship to European, African, and Native American variants. Virology. 319 (2), 315-323.

8. Calleja-Macias, I.E.; Villa, L.L.; Prado, J.C.; Kalantari, M.; Allan, B.; Williamson, A.L.; Chung, L.P.; Collins, R.J.; Zuna, R.E.; Dunn, S.T.; Chu, T.Y.; Cubie, H.A.; Cuschieri, K.; von Knebel-Doeberitz, M.; Martins, C.R.; Sanchez, G.I.; Bosch, F.X.; Munoz, N.; Bernard, H.U. (2005). Worldwide genomic diversity of the high-risk human 
papillomavirus types $31,35,52$, and 58 , four close relatives of human papillomavirus type 16. J. Virol. 79 (21), 13630-13640.

9. Clifford, G.M.; Smith, J.S.; Plummer, M.; Muñoz, N.; Franceschi, S. (2003). Human papillomavirus types in invasive cervical cancer worldwide: a meta-analysis. Br. J. Cancer. 88 (1), 63-73.

10. Clifford, G.M.; Gallus, S.; Herrero, R.; Muñoz, N.; Snijders, P.J.; Vaccarella, S.; Anh, P.T.; Ferreccio, C.; Hieu, N.T.; Matos, E.; Molano, M.; Rajkumar, R.; Ronco, G.; de Sanjosé, S.; Shin, H.R.; Sukvirach, S.; Thomas, J.O.; Tunsakul, S.; Meijer, C.J.; Franceschi, S; IARC HPV Prevalence Surveys Study Group. (2005). Worldwide distribution of human papillomavirus types in cytologically normal women in the International Agency for Research on Cancer HPV prevalence surveys: a pooled analysis. Lancet. 366 (9490), 991-998.

11. Collins, S.I.; Constandinou-Williams, C.; Wen, K.; Young, L.S.; Roberts, S.; Murray, P.G.; Woodman, C.B. (2009). Disruption of the E2 gene is a common and early event in the natural history of cervical human papillomavirus infection: a longitudinal cohort study. Cancer. Res. 69 (9), 3828-3832.

12. Das, D.; Bhattacharjee, B.; Sen, S.; Mukhopadhyay, I.; Sengupta, S. (2010). Association of viral load with HPV16 positive cervical cancer pathogenesis: causal relevance in isolates harboring intact viral E2 gene. Virology. 402 (1), 197-202.

13. de Mattos, A.T.; de Freitas, L.B.; Lima, B.M.C.; Miranda, A.E.; Spano, L.C. (2011). Diversity and uncommon HPV types in HIV seropositive and seronegative women attending an STI clinic. Braz. J. Microbiol. 42 (2), 786-793.

14. Dictor, M.; Warenholt, J. (2011). Single-tube multiplex PCR using typespecific E6/E7 primers and capillary electrophoresis genotypes 21 human papillomaviruses in neoplasia. Infect. Agent. Cancer. 6 (1), 1.

15. Elgui de Oliveira, D.; Furtado Monteiro, T.A.; Alencar de Melo, W.; Amaral Rebouças Moreira, M.; Alvarenga, M.; Bacchi, C.E. (1999). Lack of Epstein-Barr virus infection in cervical carcinomas. Arch. Pathol. Lab. Med. 123 (11), 1098-1100.

16. Frappier, L. (2011). Viral disruption of promyelocytic leukemia (PML) nuclear bodies by hijacking host PML regulators. Virulence. 2 (1), 58-62.

17. Fernandes, T.A.A.M.; Meissner, R.V.; Bezerra, L.F.; de Azevedo, P.R.M.; Fernandes, J.V. (2008). Human papillomavirus infection in women attended at a cervical cancer screening service in Natal, Brazil. Braz. J. Microbiol. 39 (3), 573-578.

18. Hudelist, G.; Manavi, M.; Pischinger, K.I.; Watkins-Riedel, T.; Singer, C.F.; Kubista, E.; Czerwenka, K.F. (2004). Physical state and expression of HPV DNA in benign and dysplastic cervical tissue: different levels of viral integration are correlated with lesion grade. Gynecol. Oncol. 92 (3), $873-880$.

19. Im, S.S.; Wilczynski, S.P.; Burger, R.A.; Monk, B.J. (2003). Early stage cervical cancers containing human papillomavirus type 18 DNA have more nodal metastasis and deeper stromal invasion. Clin. Cancer. Res. 9 (11), 4145-4150.

20. Keita, N.; Clifford, G.M.; Koulibaly, M.; Douno, K.; Kabba, I.; Haba, M.; Sylla, B.S.; van Kemenade, F.J.; Snijders, P.J.; Meijer, C.J.; Franceschi, S. (2009). HPV infection in women with and without cervical cancer in Conakry, Guinea. Br. J. Cancer. 101 (1), 202-208.

21. Kim, N.R.; Lin, Z.; Kim, K.R.; Cho, H.Y.; Kim, I. (2005). Epstein-Barr virus and p16INK4A methylation in squamous cell carcinoma and precancerous lesions of the cervix uteri. J. Korean. Med. Sci. 20 (4), 636642.

22. Kjær, S.K.; Frederiksen, K.; Munk, C.; Iftner, T. (2010). Long-term absolute risk of cervical intraepithelial neoplasia grade 3 or worse following human papillomavirus infection: role of persistence. J. Natl. Cancer. Inst. 102 (19), 1478-1488.

23. Li, N.; Franceschi, S.; Howell-Jones, R.; Snijders, P.J.; Clifford, G.M. (2011). Human papillomavirus type distribution in 30,848 invasive cervical cancers worldwide: Variation by geographical region, histological type and year of publication. Int. J. Cancer. 128 (4), $927-$ 935.

24. Lu, J.; Murakami, M.; Verma, S.C.; Cai, Q.; Haldar, S.; Kaul, R.; Wasik, M.A.; Middeldorp, J.; Robertson, E.S. (2011). Epstein-Barr Virus nuclear antigen 1 (EBNA1) confers resistance to apoptosis in EBVpositive B-lymphoma cells through up-regulation of survivin. Virology. 410 (1), 64-75.

25. Münger, K.; Howley, P.M. (2002). Human papillomavirus immortalization and transformation functions. Virus. Res. 89 (2), 213 228.

26. Muñoz, N.; Bosch, F.X.; de Sanjosé, S.; Herrero, R.; Castellsagué, X.; Shah, K.V.; Snijders, P.J.; Meijer, C.J.; International Agency for Research on Cancer Multicenter Cervical Cancer Study Group. (2003). Epidemiologic classification of human papillomavirus types associated with cervical cancer. N. Engl. J. Med. 348 (6), 518-527.

27. Nagao, S.; Yoshinouchi, M.; Miyagi, Y.; Hongo, A.; Kodama, J.; Itoh, S.; Kudo, T. (2002). Rapid and sensitive detection of physical status of human papillomavirus type 16 DNA by quantitative real-time PCR. $J$. Clin. Microbiol. 40 (3), 863-867.

28. Ordóñez, R.M.; Espinosa, A.M.; Sánchez-González, D.J.; ArmendárizBorunda, J.; Berumen, J. (2004). Enhanced oncogenicity of AsianAmerican human papillomavirus 16 is associated with impaired E2 repression of E6/E7 oncogene transcription. J. Gen. Virol. 85 (6), 14331444.

29. Pett, M.; Coleman, N. (2007). Integration of high-risk human papillomavirus: a key event in cervical carcinogenesis? J. Pathol. 212 (4), 356-367.

30. Ruutu, M.P.; Kulmala, S.M.; Peitsaro, P.; Syrjänen, S.M. (2008). The performance of the HPV16 real-time PCR integration assay. Clin. 
Biochem. 41 (6), 423-428.

31. Santos, N.B.; Villanova, F.E.; Andrade, P.M.; Ribalta, J.; Focchi, J.; Otsuka, A.Y.; Dale Silva, I. (2009). Epstein-Barr virus detection in invasive and pre-invasive lesions of the uterine cervix. Oncol. Rep. 21 (2), 403-405.

32. Schwartz, S.M.; Daling, J.R.; Shera, K.A.; Madeleine, M.M.; McKnight, B.; Galloway, D.A.; Porter, P.L.; McDougall, J.K. (2001). Human papillomavirus and prognosis of invasive cervical cancer: a populationbased study. J. Clin. Oncol. 19 (7), 1906-1915.

33. Seo, S.S.; Kim, W.H.; Song, Y.S.; Kim, S.H.; Kim, J.W.; Park, N.H.; Kang, S.B.; Lee, H.P. (2005). Epstein-Barr virus plays little role in cervical carcinogenesis in Korean women. Int. J. Gynecol. Cancer. 15 (2), 312-318.

34. Sima, N.; Wang, S.; Wang, W.; Kong, D.; Xu, Q.; Tian, X.; Luo, A.; Zhou, J.; Xu, G.; Meng, L.; Lu, Y.; Ma, D. (2007). Antisense targeting human papillomavirus type 16 E6 and E7 genes contributes to apoptosis and senescence in SiHa cervical carcinoma cells. Gynecol. Oncol. 106 (2), 299-304.

35. Szkaradkiewicz, A.; Wal, M.; Kuch, A.; Pieta, P. (2004). Human papillomavirus (HPV) and Epstein-Barr virus (EBV) cervical infections in women with normal and abnormal cytology. Pol. J. Microbiol. 53 (2), 95-99.

36. Thierry, F.; Demeret, C. (2008). Direct activation of caspase 8 by the proapoptotic E2 protein of HPV18 independent of adaptor proteins. Cell. Death. Differ. 15 (9), 1356-1363.

37. Thierry, F. (2009). Transcriptional regulation of the papillomavirus oncogenes by cellular and viral transcription factors in cervical carcinoma. Virology. 384 (2), 375-379.

38. Thompson, S.; Messick, T.; Schultz, D.C.; Reichman, M.; Lieberman, P.M. (2010). Development of a high-throughput screen for inhibitors of Epstein-Barr virus EBNA1. J Biomol. Screen. 15 (9), 1107-1115.

39. Travasso, C.M.; Anand, M.; Samarth, M.; Deshpande, A.; Kumar-Sinha, C. (2008). Human papillomavirus genotyping by multiplex pyrosequencing in cervical cancer patients from India. J. Biosci. 33 (1),
$73-80$

40. Velázquez-Márquez, N.; Jiménez-Aranda, L.J.; Sánchez-Alonso, P.; Santos-López, G.; Reyes-Leyva, J.; Vallejo-Ruiz, V. (2010). Human papillomavirus infection in women from Tlaxcala, Mexico. Braz. J. Microbiol. 41 (3), 749-756.

41. Vinokurova, S.; Wentzensen, N.; Kraus, I.; Klaes, R.; Driesch, C.; Melsheimer, P.; Kisseljov, F.; Dürst, M.; Schneider, A.; von Knebel Doeberitz, M. (2008). Type-dependent integration frequency of human papillomavirus genomes in cervical lesions. Cancer. Res. 68 (1), 307313.

42. Wang, C.C.; Lai, C.H.; Huang, H.J.; Chao, A.; Chang, C.J.; Chang, T.C.; Chou, H.H.; Hong, J.H. (2010). Clinical effect of human papillomavirus genotypes in patients with cervical cancer undergoing primary radiotherapy. Int. J. Radiat. Oncol. Biol. Phys. 78 (4), 1111-1120.

43. Watts, K.J.; Thompson, C.H.; Cossart, Y.E.; Rose, B.R. (2002). Sequence variation and physical state of human papillomavirus type 16 cervical cancer isolates from Australia and New Caledonia. Int. J. Cancer. 97 (6), 868-874.

44. Woodman, C.B.; Collins, S.; Rollason, T.P.; Winter, H.; Bailey, A.; Yates, M.; Young, L.S. (2003). Human papillomavirus type 18 and rapidly progressing cervical intraepithelial neoplasia. Lancet. 361 (9351), 40-43.

45. Xue, Y.; Bellanger, S.; Zhang, W.; Lim, D.; Low, J.; Lunny, D.; Thierry, F. (2010). HPV16 E2 is an immediate early marker of viral infection, preceding E7 expression in precursor structures of cervical carcinoma. Cancer. Res. 70 (13), 5316-5325.

46. Yang, Y.Y.; Koh, L.W.; Tsai, J.H.; Tsai, C.H.; Wong, E.F.; Lin, S.J.; Yang, C.C. (2004). Correlation of viral factors with cervical cancer in Taiwan. J. Microbiol. Immunol. Infect. 37 (5), 282-287.

47. zur Hausen, H. (2000). Papillomaviruses causing cancer: evasion from host-cell control in early events in carcinogenesis. J. Natl. Cancer. Inst. 92 (9), 690-698.

48. zur Hausen, H. (2002). Papillomaviruses and cancer: from basic studies to clinical application. Nat. Rev. Cancer. 2 (5), 342-350. 